The Journal of Academic Librarianship, 1998, Vol. 24, Issue 2, p.113-120.

ISSN: 0099-1333

http://www.sciencedirect.com/

http://www.sciencedirect.com/science/article/pii/S0099133398901719

http://dx.doi.org/10.1016/S0099-1333(98)90171-9

(C) 1998 The Journal of Academic Librarianship

\title{
Using Automation in Technical Services to Foster Innovation
}

\author{
by Carol Pitts Diedrichs
}

Current conditions impel technical services librarians to consider new ways of doing business, to foster innovation, and to implement innovative ideas. New approaches such as outsourcing and centralizing selection, OCLC's Passport for Windows, and OCLC's PromptCat illustrate the process of facilitating and fostering new ways of thinking about technical services processes.

Why is innovation important for technical services today? In libraries today, conditions such as the economic climate and the speed of technological change, as well as changing patron expectations, demand a new approach to technical services. With more limited monetary and human resources, libraries are struggling to provide the services and materials offered in the past, as well as new services. The business world has been forced to downsize and restructure in order to remain competitive. Libraries do not see themselves as being in a competitive business because libraries do not usually compete with other libraries for patrons. But, the reality is that libraries are in a competitive environment with other information providers. Libraries must innovate to remain competitive.

Vendors are in a competitive business so they must evaluate and implement changes and new options faster than in the past. For example, The Ohio State University Libraries (OSUL) was an early test site for OCLC's PromptCat. The library tested the product in early 1994 and made a decision at that time that it was an innovation that would be adopted to free staff for more complex cataloging. However, OSUL had to first wait for Innovative Interfaces, Inc. (III) to write the necessary programming to incorporate the new product. Once that programming was available, the Libraries' approval vendor, Baker \& Taylor, was in the midst of a system change which precluded them from completing their implementation of the product. Finally, in 1997, the Libraries are in the actual implementation stage of a product which was tested and adopted in 1994. However, the reverse situation is also prevalent. Vendors have more options and services to offer than a library has time to consider and evaluate.

This infiltration of technology into the lives of most individuals has also resulted in changing patron expectations. Students now come to campus or to the local public library with extensive PC skills. They are accustomed to a video culture which values action, speed, and instant gratification. Patrons are no longer content to be told that a title can be requested for them or that it will arrive in two weeks. The availability of information in electronic form has increased the pressure on public services librarians to provide support and training for these electronic products. In many libraries, that pressure has been translated into the need to transfer positions from technical services to public services to meet the demand for services. Automation departments are 
pressured to upgrade hardware and software constantly to stay abreast of what users expect (e.g., graphical user interfaces) as well as the technological demands of the electronic products. The Acquisition Department at OSUL has experienced these increased demands in the speed with which it is expected to investigate, negotiate, and provide electronic resources for patrons. In the past, it was not unreasonable to expect a 30 to 90 day turnaround for the order and receipt of new books. Today, collection development librarians expect electronic products to be made available almost immediately on request. The ready availability of information on the Internet, particularly the explosion of the Web as a tool for acquiring material, has already expanded, and will continue to expand, expectations. In addition, libraries must find the financial resources to provide those new tools. Technical services and collection development librarians are keenly aware of the declining purchasing power of library materials budgets. For example, the materials budget for serials at OSUL was increased from \$3.45 million in FY94 to \$4.46 million in FY97, but that amount purchased almost exactly the same number of titles throughout the four year period.

In Carlen Ruschoff's ${ }^{1}$ article about the forces which are shaping technical services specifically, she identifies one, the ambition of librarians to do more, which is certainly admirable but not without consequences. It is a credit to the profession that librarians are so customer service oriented and that is one reason that libraries should continue to be successful. However, librarians have to realize the importance of making choices among various options. Every technological advancement that a vendor or OCLC makes available provides new innovative ways for technical services to consider doing business. It is easy to be blinded by the glitter of these new initiatives.

\section{"Technical services librarians need to be encouraged to embrace change and look for ways to improve continuously what they do."}

Technical services librarians need to be encouraged to embrace change and look for ways to improve continuously what they do. However, every change and innovation has an implementation stage that is essential to success. Each option has start up costs, maintenance costs, and costs in terms of staff time. As a result of these forces, the 1990s have clearly seen a shift to a new series of change motivators within technical services: the use of the Internet and the Web in technical services, outsourcing and other new services from vendors and suppliers, and new ways of looking at the way business is conducted. The current value placed on timeliness and efficiency leads to increasing dissatisfaction with existing backlogs and the time required to process material. Patron expectations reflect their familiarity with more instant gratification; in the past librarians dealt with patrons who did not want to use a computer, now users complain when they have to search a paper index. For example, during the Libraries' annual budget hearing several years ago, the Provost raised an unexpected question: How long does it take to get a book to the shelves? The Libraries were somewhat disheartened by the first answer to that question when an evaluation was done. However, the question resulted in a concerted effort to reduce the time to less than one week for a high percentage of the English language material received.

Not every innovation is successful. Librarians must be prepared to take risks, experience failure, and try again. For example, in the 1980s, researchers experimented with expert systems designed to perform original cataloging. The thinking at the time was that artificial intelligence could be applied to original cataloging in such as way that all activities would be performed by the machine making cataloged obsolete. It is clear in the 1990s that expert systems and tools such as the LC's Catalogers' Desktop will facilitate and improve the process of original cataloging, but such systems are unlikely to be sophisticated enough to replace catalogers at this juncture. ${ }^{2}$ 


\section{Fostering Innovation}

Innovation has a variety of definitions. Thomas D. Kuczmarski believes that "innovation is best described as a pervasive attitude that allows businesses to see beyond the present and create a future vision. ${ }^{3}$ When the leadership of an organization or even a single department has an innovative mind set, that mind set can be transmitted over time to the people working with those individuals. A key factor for instilling an innovative mind set in technical services is working with staff to ensure that they see that their work has an impact on the patron. Innovation has to become an integral part of the way managers approach each problem and work with each issue facing their organizations. Successful innovation in technical services involves three key components: the ability to envision the future, the use of intuitive thinking and creativity, and well-managed implementation.

\section{Envisioning the Future}

How does a manager foster innovation? Envisioning the future is a key first step in fostering innovation. Envisioning the future may sound a bit grand; envisioning a goal may be an easier way to get started. Successful innovation will result in changes to the way people do their jobs. To be successful, the people who have to make a strategy or vision work must be integral to the process of developing that strategy. Convincing people even to consider the strategy, particularly one that is new and different, is a major task. Librarians will be challenged to convince lower-level staff about the need for change, but will also be called upon to convince supervisors, upper-level administration, and peers that a new approach is warranted. In technical services, the idea of accepting approval material without review or with no return options, is currently very popular. Not only must acquisition staff be persuaded that this is a viable alternative to consider but collection managers must also be persuaded.

\section{"How does a manager foster innovation? Envisioning the future is a key first step in fostering innovation."}

The purpose of a vision is to excite and inspire those who work for the department as well as state the fundamental values which will permeate every decision, policy, or action of the department. ${ }^{4}$ For example, a vision which could be written for the OSUL Acquisition Department might read as follows: to provide the best acquisition, receipt, invoicing, cataloging, project control, and management services so that the department can help the collection managers deliver high quality service to the University's patrons. A vision for a particular goal can help picture what things will be like once the mission is accomplished. In 1996, the Copy Cataloging Section was merged with the Acquisition Department. Following that merger, the department had a vision of eliminating an eight week copy cataloging backlog and maintaining a one week turnaround on that material for the future. In looking to the attainment of that goal, the staff knew that if they eliminated the copy cataloging backlog, there would not be as much opportunity to misplace an unprocessed book. The department would be able to locate rush material more quickly or actually have already processed the rush title by the time the rush request was received. The department would not receive as many complaints or be considered inefficient. Instead, the department would be considered a department with a good service attitude and reputation as well as a place where a collection manager could get real help and assistance. 
Another part of envisioning the future includes an assessment of the environment, culture, and values. What works for one library may not work for another library. Two strategies are particularly effective for overcoming the restrictions of culture, environment, and values: de-emphasizing former priorities ${ }^{5}$ and ignoring conventional wisdom. ${ }^{6}$ The following examples illustrate these two strategies.

\section{De-emphasizing Former Priorities: Online Entry of Order Requests}

A recent innovation implemented at OSUL is the use of new security software in the III system to allow the direct, online entry of order requests by the 40+ collection managers or their staff. Until now, collection managers had been restricted to paper orders which required typing on $3 \times 5$ forms in each branch library and then retyping in the order entry process. In the past, one of the Acquisition Department priorities was to require the submission of a paper Materials Request Form for each order request submitted to the department. This requirement met the internal auditor's stipulations for a collection manager's signature on each order request. The new workflow de-emphasizes the importance of the paper order request and focuses on new goals of issuing orders more quickly and eliminating redundant keying and subsequent errors.

The department's vision of the future included the development of III security software which would allow the collection managers to key their order requests directly into the system. With this new security software, the department would be able to eliminate the submission of paper orders, reduce the transit time for the orders to arrive from the collection managers, eliminate the occasional loss of paper order requests in the campus mail system, and capture information once at the point of entry in the system rather than multiple rekeyings. This new system software confines the collection managers or their staff member to the order entry process and does not allow updating of existing orders. The order requests they enter are given a provisional status which precludes them from actually being placed as a order at that point. These orders are collected each morning in the Acquisition Department through a Boolean report and printed. When the verification process is complete, the bibliographic searcher locates an appropriate OCLC record, overlays the initial record in the system with the OCLC one, updates the order record with their findings, assigns a vendor from a pre-established list, and initiates the order.

The Acquisition Department tested this new procedure initially with a few different collection managers who represent different approaches and concerns in their selection process. This test has helped the department address issues such as where should information be placed in the record and what should be done about additional printed information (e.g., publisher flyers) which may be needed in the order process. This new process has created major change and challenge for the entire monograph processing workflow. In the past, the paper order request form submitted by the collection manager traveled with the piece through the entire technical processing flow and back to the collection manager. One significant question to be addressed is what purposes did this piece of paper serve in the past and how will those purposes still be accommodated in the new process? For example, in the past, OSU's internal auditors had required the department to keep one copy of the paper order request as proof of order authorization by the collection manager. To address this issue, the electronic data processing auditor will be consulted for an evaluation of the revised workflow that eliminates this paper form. The absence of the paper form in the cataloging process will mean that the authority for information such as location code and other processing instructions will reside in the online system rather than on the original paper form 
submitted by the collection manager. In the past, OSU's cataloging operations have not relied on the online system for information so many procedures will have to be revised and reevaluated to make this transition.

Finally, a number of the collection managers have used one copy of the original order request as a local order file. This was useful because they had to send their orders by campus mail resulting in a greater potential for loss before those orders ever reached the Acquisition Department. When the books arrived in their location, the original order request was pulled from the file leaving only the material still outstanding. With online order request entry, the campus mail process will no longer be an issue. That will be a plus; however, it also means that collection managers will need to rethink the ways they have been using their order files. The Acquisition Department and the Automation Office have provided training in report generation to collection managers; with this new process, they will be given new training and suggestions on how they can use the system to determine the status of outstanding orders. This new process combined with other innovations (the use of PromptCat and Passport for Windows) has the potential for a dramatic realignment and entirely new vision for OSU's entire monograph processing workflow.

\section{Ignoring Conventional Wisdom: Passport for Windows from Oclc}

A second strategy for implementing change, ignoring conventional wisdom, has been used in the implementation of Passport for Windows. In the past, the conventional wisdom at OSUL was that on receipt of the piece all of the bibliographic work done previously was ignored. Even though the OCLC number had been keyed into the order record, that information was not used in the cataloging process. In essence, the person cataloging the title did not make use of the information found earlier but started the entire process of searching OCLC over again. Several years ago, Marsha Hamilton, Head of the Monograph Acquisition Division of the Acquisition Department, conducted an informal study comparing the OCLC record selected at the point of order with the OCLC record later used for cataloging. Her findings revealed that well over $90 \%$ of the OCLC records identified at the point of order were subsequently used to catalog the piece. This study helped convince individuals in technical services that the conventional wisdom was in need of reconsideration.

A standard part of the bibliographic verification process for order records at OSUL is the upgrading of the bibliographic record in the online catalog to reflect information found in OCLC. These order records are displayed to the public from the moment that the order is issued and serve as the only bibliographic information about the title for years if it cannot be cataloged quickly on receipt. OCLC's Passport for Windows uses the Internet to download bibliographic records into the library's online catalog immediately (in real time) rather than by tapeload. This product is used at the front end of the order process to retrieve full bibliographic records from OCLC for use as the base bibliographic record for an order. For the acquisitions process, this has immediate benefits: brief bibliographic records no longer have to be keyed into the system for each order. For a high percentage of orders, the title could be located in OCLC, downloaded immediately to the III system, an order record attached, and the order issued electronically or in paper. In the past,

Acquisition used a team of students to key each record into the system. In addition to the savings in keying, the errors introduced anytime a title had to be rekeyed have been reduced. Foreign language entry has become vastly simpler and more accurate. In some cases, where collection managers are also catalogers or very knowledgeable in their field (e.g., OSU's language or music specialists), the collection managers actually select the OCLC record to be used for their order. 
Thus, the bibliographic information for the orders is much more accurate.

With the implementation of Passport for Windows to download an OCLC record at the point of order, technical services also took the opportunity to evaluate and implement cataloging on receipt. In many cases, the correct bibliographic record was being selected and added to the system before the piece even arrived. Thus, by combining the receipt and copy cataloging processes, material moves more quickly to the shelves with fewer handlings. At this point, copy cataloging at receipt occurs throughout the Acquisition Department including titles received on approval and firm order and as gifts. The conventional wisdom that acquisition staff do not have bibliographic expertise or that cataloging staff cannot interpret order records is no longer valid.

"The second key component is the use of intuitive thinking and creativity."

\section{Intuitive Thinking and Creativity}

The second key component is the use of intuitive thinking and creativity. When new trends are emerging, people who can think intuitively are especially valuable. They are the people who first ask questions such as: Do approval titles really have to be reviewed by collection managers? Intuition has been defined as the ability to see the woods not just the trees, to see the big picture, and to grasp opportunities. Although intuition is often hard to define, "most would agree that intuition is:

- A quick or ready insight or new idea, based in some way on past experience, feelings, and memories;

- A kind of understanding gained without recourse to the usual processes of rational thought;

- A way of arriving at conclusions on the basis of limited information; and

- Something you are born with, but which can be developed and extended."7

Today's library environment involves a high level of uncertainty, has few precedents on which to base decisions, often lacks reliable facts to guide decisions, requires quicker decisions with less time for reflection, and often offers several plausible options to consider. Individuals who are able to use their intuition rather than requiring hard facts on which to base every decision will be the most successful technical services managers of the future.

Creative breakthroughs are most likely to occur when individuals have time to think about things away from the work at hand and the day to day crisis. Few librarians have the luxury of scheduling in a little "thinking" time during the course of the work day. Instead, librarians must look for other opportunities to "think" such as being stuck in traffic, driving on a trip, or exercising. It is during these "thinking" times that flashes of insight occur. For example, one of these flashes occurred for the author recently when two events converged to create a new opportunity. In the first event, complaints expressed by Acquisition Department staff about the problems they were experiencing with the Libraries' mailroom operations had accelerated to a new high. In the past, the author had always resisted taking on the burden of unpacking the material destined for the Acquisition Department because there was no staff, time, or space for the activity. The author's "Eureka" moment came when she realized that a recent retirement would allow the department to 
redefine a position so that the current responsibilities of the existing job as well as supervision of the students for unpacking the mail could be combined. The staff and time aspects of this issue were resolved as a result of a unexpected retirement; the space issue had already been resolved because new space was available as a result of the elimination of the copy cataloging backlog mentioned earlier.

Fostering creativity and innovation depend on a culture where new ideas are solicited, valued, and encouraged. Failures will occur, but these too must be handled with care or staff will fear proposing new ideas or approaches. For instance, the assembly line at a laser drum assembly company in Ohio uses a process that is repetitive on the shoulder resulting in injuries. The line already had pneumatics installed for other purposes and an employee recommended that the pneumatics be used for this operation instead of putting all of the stress on the shoulders of the workers. Her strategy was implemented and has been a big success. That may seem pretty routine, but what is not routine is the pride with which the employee reported this success to her family at Thanksgiving and then again just before Christmas when she was acknowledged publicly at the company picnic. The principle of acknowledging creativity crosses many kinds of organizations including libraries.

\section{Innovation through Outsourcing: PromptCat}

One of the most interesting innovations under discussion in technical services at this time is the use of OCLC's PromptCat service for the delivery of bibliographic records with approval and firm order shipments and the delivery of firm order and approval material shelf-ready. OCLC's PromptCat service takes the vendor's list of titles shipped, searches them automatically against its database using an algorithm that selects an appropriate record and delivers that record to the library. The library has a series of options available with the Prompt-Cat service such as which category of copy it prefers including Library of Congress (LC) records, cataloging-in-publication (CIP), member, or a combination. The library can also specify the time period for setting the holdings on OCLC, that is, immediately or 21 days after shipment. These options allow libraries to customize the service to their preferences.

\section{"One of the most interesting innovations under discussion in technical services at this time is the use of OCLC's PromptCat service for the delivery of bibliographic records with approval and firm order shipments and the delivery of firm order and approval material shelf-ready."}

PromptCat is obviously a creative new approach to processing material that is likely to have readily accessible copy in OCLC at the time the book is received. The service can be evaluated from several perspectives: is it cost-effective or cheaper than the library's traditional processing of material or would its implementation (at a higher cost) expand the volume of cataloging or other activities which could be performed by the same number of staff? Several libraries evaluated the PromptCat service offered by OCLC and rejected it because they felt that their speed, efficiency, and costs for processing approval material would not be improved upon by using an external service. On the other hand, other libraries determined that the cost of processing material via PromptCat was cheaper than their internal process. At OSU, the Acquisition Department can process approval materials at a cost similar to the charges expected from OCLC. However, OSUL is in the process of implementing PromptCat in order to redirect staff to other 
cataloging priorities.

Michigan State University (MSU) and Ohio State University were the first two libraries to test this service. In OSU's test, $91 \%$ of the records chosen by the Prompt-Cat software matched one-to-one with those chosen by OSU. For the remaining 9\%, OCLC had supplied two records, one of which matched OSU's choice. OSU also did some additional testing of the searching algorithm. In all but one case, the record OSU would have selected matched the record with the highest match rate from the algorithm. ${ }^{8}$ Kay Granskog (MSU) has indicated that records were received for $99.4 \%$ of the titles in their test; $40 \%$ of those were full level LC records which required no revision. ${ }^{9}$ This $40 \%$ figure is lower than expected because at the time of this test, CIP records formed a large percentage of the records being delivered. As a result, they required some revision before cataloging could be completed.

Beginning in December 1995, OCLC addressed the CIP problem by installing professional catalogers with major approval plan vendors, Academic Book Center and Yankee Book Peddler, to upgrade the catalog records for books those vendors were handling. Reba Leiding stresses that a smaller library which uses notification slips exclusively will have an even greater chance of receiving full level records since more time passes between the time of publication and the receipt of the title ordered from a notification slip. Leiding tracked the type of record received at Ferris State University, an early PromptCat user, beginning in October 1995. "The percentage of records matched always was around 95\%. The percentage of CIP records dropped from around $25 \%$ at the beginning of Prompt-Cat service to 5\% in April 1996, while the percentage of full cataloging records rose from $66 \%$ to more than $80 \%$. (Note that this all took place before OCLC installed catalogers to upgrade records on Yankee's premises. $)^{10}$

The implementation of a service like PromptCat is maximized when the library also evaluates the impact of the new service on the existing workflow. Just as libraries were cautioned against moving paper-based workflows to their new integrated library systems, these new products must be implemented with an eye to rethinking the entire process often described as "thinking outside the box." PromptCat delivers an fully cataloged record at the time a book is received. As a result, the OCLC search for acceptable copy and the settings of holdings is already completed. The person processing the title need only review the record selected for a match, complete any local editing, and process the title for the shelf. Thus, by combining the receipt and cataloging, all of the relevant information remains with a single person and does not have to be moved from area to area for completion of the process. In addition to moving a high percentage of approval material to the shelves faster, errors can be reduced as well. ${ }^{11}$ At OSU a majority of the titles received with acceptable copy are processed within one week and copy catalogers have been freed to focus on more complex copy cataloging. In addition, OSUL has been able to increase the volume of material cataloged as a result of PromptCat and the implementation of cataloging on receipt.

\section{Additional Outsourcing: Shelf-Ready Materials}

At least two other libraries have taken the use of PromptCat or vendor-supplied records for approval titles a step further in the innovation cycle. Louisiana State University (LSU) consolidated its approval and firm order vendors into a single primary vendor, Yankee Book Peddler (YBP), which was able to participate in PromptCat and could provide a full range of shelf-ready options. LSU plans to take this consolidation a step further by also moving its standing order titles to YBP. While these were with another vendor, they formed the primary source of unintentional duplicates. At LSU, selectors still review titles but because the titles are received 
shelf-ready, they can only be returned if damaged. The other purpose of this review is to allow for refinement of the approval profiles. LSU has also experienced a problem with mismatches caused by the OCLC algorithm used to identify and match records with the information provided by the vendor. Although the percentage is small (1.4\%), LSU has worked with OCLC to refine the algorithm to reduce this percentage even further. For each mismatch, the holdings have to be removed, OCLC has to be searched for appropriate copy, the record must be exported and the holdings added again. Each transaction carried additional costs. Alleviating these problems is important to LSU because they will be implementing a spine labeling process which will make the material unreturnable. ${ }^{12}$

For some libraries, the LSU project is too bold a move. As an alternative, Charles Wittenberg ${ }^{13}$ has advocated a multi-step process to rethinking the approval plan. The first reaction of some collection managers may be that there is no point to having an approval plan if the collection manager loses the right to return books. From his perspective, the solution might be to go to an all-slips plan. However, this solution obviates one of the key benefits of approval plans - not having to place an order. Wittenberg proposes that libraries begin to think of approval plans as blanket plans instead. To maximize the effectiveness of such a shelf-ready blanket plan, the acceptable return rate has to be managed aggressively to bring it as close to zero as possible. Good candidates for moving to a comprehensive purchase plan with no returns is the library with a mature approval profile and a very low return rate. If the plan can be tightly refined so that the return rate is modest, the cost of these unwanted items can be seen as collection development's contribution to the reengineering process. Another approach to the financial aspect is to take the financial bite of those returns out of a central fund that does not directly impact the purchasing power of each collection manager.

Where return rates are higher, the library can take a multi-stepped approach to the process. Wittenberg advocated a three-tiered plan with materials falling into three categories: keepers, lookers, and slips. Keepers are categories of materials such as university press titles which can arrive processed and ready for the shelf. Lookers arrive unprocessed and are made available through a traditional approval review process. As with regular approval plans, slips are sent in lieu of books for categories where there is the most uncertainty. Of course, the goal of this strategy is to increase continually the number of titles which can be defined as "keepers." This is an excellent example of the way in which a creative idea can be explored and examined in the context of the individual library's values and culture.

The University of Akron has implemented the approach advocated by Wittenberg using Blackwell North America as its vendor. The "keepers" are delivered shelf-ready, with records from the Library of Congress, vendor-upgraded CIP records, and electronic invoicing. At the University of Akron a variety of individuals involved in the implementation had decidedly different reasons for believing this innovation would be effective and valuable. These examples illustrate the varied perspectives that influence and impact individuals' ability to think creatively:

- Collection Management was interested because the records included additional fields which provided increased access points on the III system;

- Cataloging and Physical Processing saw an opportunity to increase their productivity by focusing on other areas;

- Public Services believed that materials would be available more quickly for users; and

- Acquisitions was interested in eliminating some of the handling and, thus, decrease processing time. $^{14}$ 
- This is a good example of taking a theoretical idea (e.g., Wittenberg's) and implementing it in a real library.

\section{Well-Managed Implementation}

Most librarians have had experience with creative thinkers who always have new ideas and, in some cases, seem willing to implement new ideas regardless of the potential outcome, often just because they seem like interesting new ideas. Innovation is different from creativity. Creativity includes activities such as brainstorming and thinking without the constraints of implementation. Creativity and idea generation do not necessarily imply innovativeness; innovation is also the implementation of those ideas in the working environment. ${ }^{15}$ Each innovation must be supported by an implementation process that takes the idea step by step through each aspect and works out the problems so that the innovation is successfully implemented. The idea must move from the conceptual stage right through to production. ${ }^{16}$ Libraries need both creativity and innovation; they need staff to think beyond the box but also with a realistic view to how something could be implemented. Some innovations are actually rather small and do not require extended discussion or implementation. This ability to make daily and independent adjustments for improvement is often labeled as empowering staff. Although that term may have been overused, its meaning - instilling personal responsibility in each staff member - is critical to successful innovation. Staff need to think that they are responsible for looking for ways to improve processes and services in everything they do.

\section{Outsourcing of Selection: Hawaii/B\&T Contract}

The implementation process can best be illustrated by two case studies. Much has been written about the first example, the March 1996 ground breaking decision of the Hawaii State Public Library System (HSPLS) ${ }^{17}$ to outsource its entire selection process and materials budget as well as the processing activities (acquisition, cataloging, and physical processing) to a single vendor, in this case, Baker \& Taylor (B\&T). HSPLS signed a $5^{1 / 2}$ year contract with B\&T to supply $\$ 11.2$ million in books for its main library and 48 branches. The B\&T contract charges a flat fee of \$20.94 per book which includes all processing. Selection for titles of regional interest has been subcontracted to a local supplier, Booklines Hawaii. Controversy has swirled around the decision, its implementation, and the transition problems. The primary objection from librarians is that selection, one of the most professional duties of a librarian, was placed in the hands of a vendor. HSPLS says that the decision was made as a means of saving money and making materials available faster. State Librarian Bart Kane has indicated that the deal was made as a part of a reengineering effort prompted by a $25 \%$ budget cut from the governor. The alternative would have been layoffs and the possibility of closing many branches. Others have disputed these facts, particularly the level of the cuts expected. Staff have also indicated that recommendations for streamlining were ignored and that field staff were not consulted in the reorganization and outsourcing decision-making process. Kane contends that extensive communication occurred through a variety of forums. As a result of the controversy, the state's Senate Education Committee ordered an audit of the contract. In summer 1997, the Hawaii Board of Education endorsed a recommendation to cancel the contract and HSPLS cancelled the contract. 
The problems identified with the process (other than the philosophical objections) reflect some concrete implementation issues:

- Materials received did not match community interests;

- Librarians were hampered in their ability to serve as readers' advisors because the selection process kept them familiar with what was being published;

- B\&T cataloging was inconsistent in quality;

- Gift books could not be added to the collection because there was no provision for cataloging them;

- No discretionary funds existed to allow the branches to buy locally requested material or to replace lost and damaged material; and

- Many duplicates have been received.

Supporters have countered that the kinks could be worked out. B\&T also had a series of explanations for the problems encountered to date;

- When the outsourcing began, HSPLS selection of a new automation vendor had been held up by a protest from a vendor not selected. As a result, B\&T had no access to the database of existing materials, but was required to expend the existing funds in the 1996 fiscal year. B\&T had to select and review 60,000 titles in a three month period without access to the system. The duplicates resulted during this time period. B\&T contends that this level of duplication will not be a problem in the future.

- A Selection Advisory Committee was set up after the contract was in effect that includes B\&T librarians as well as Hawaii librarians. A weekly conference call was held to review selection lists and make adjustments.

- In early 1997, the State Library advertised for a cataloger whose duties would include cataloging gift books.

- B\&T has indicated that deeper levels of profiles were needed than were initially constructed.

- Local libraries have been given permission to use money from fines and friends groups to purchase some material.

Regardless of the impetus for this innovative idea, the idea of reconsidering and reexamining the activity of selecting materials for a library is a clear example of "thinking outside the box." However, it is also a clear example of the damage done by poor implementation of a idea worthy of evaluation. One of the reasons that the actions of the HSPLS have resulted in so much discussion and controversy is that this examination forces librarians to look carefully at a long-standing activity within which very little innovation has occurred. Librarians see selection as a core activity at the very heart of librarianship. In evaluating this from the perspective of using automation in technical services to foster innovation, two primary areas emerge for consideration: 
- How could the philosophical question of whether selection can be outsourced have been better addressed with those most effected by it?

- Once a decision was made, how could the innovation/implementation process have been improved?

It is also obvious that the constraints for spending the remainder of the FY96 budget without access to the database resulted in significant implementation problems which only further inflamed the opponents of the process. The implementation also bears the marks of having been implemented top down without adequate discussion and input from the individuals that actually have to make the process work on the frontline.

\section{Centralization of Selection: Indianapolis-Marion County Public Library}

In contrast, the project implementation for a centralized selection process in place at the Indianapolis-Marion County Public Library (IMCPL) ${ }^{18}$ was much more successful. This library addressed the issue of juggling available funds and the plethora of purchase choices by implementing centralized selection for the main library and all branches. The biggest fear surrounding centralized selection was the fear that all branches would look exactly alike with no opportunity for diversity as it relates to the particular community being served. At the beginning of the process, IMCPL hired a collection development librarian to coordinate everything. Initially, she spent four days in each branch to familiarize herself with their collections and specific needs. On an ongoing basis, she spends time each year in each branch working with the staff, working the reference desk, and analyzing the collection to look for dated and weak areas. Each branch is expected to communicate its special needs to the collection development librarian. Branch librarians have unlimited rights to request titles to replace a lost or missing title or because the title was not supplied through the centralized selection process.

As part of implementing centralized selection, IMCPL had subject areas that they wanted to change through centralized selection. Before implementation, the library administration thought that they were weak in the science and technology areas because many librarians were put off by the high costs. In other cases, the branch librarians had liberal arts backgrounds and felt unqualified to evaluate prospective titles. Personal bias was also evident; for example, they were afraid that they were not paying enough attention to the male patrons. They were also surprised to find that subjects that had routinely been collected only for the main library were in demand at other branches once readily available there. Resistance was expected and accepted, but the outcome of that resistance was unanticipated. "When centralized selection began, librarians at one branch were up front about their keeping track of the titles they were receiving that they thought would not circulate. They later admitted that they had thrown the slips away after one year because indeed the materials were circulating. One of the most articulate opponents of centralized selection

agreed that it was wonderful for computer books, confessing, "I never had a clue in that area." ${ }^{19}$ An unexpected problem was how to deal with saturation levels - when is enough material on a topic enough? These last two quotes seem an appropriate summation of that problem:

- "How was I to know that that would be the book that told the world that J. Edgar Hoover like to wear dresses?' the CDL once complained;" and

- "One [branch librarian] has sent written instructions that she doesn't want another Elvis book even if it proves that he is alive.",20 
IMCPL was also concerned that their choice of centralized selection not be perceived as a "give 'em what they want" selection philosophy. An emphasis on meeting public demand does not mean that only a few titles with hundreds of copies are purchased. Of the approximately 14,000 titles which are purchased annually, only seven to nine titles per month fall into the category of being purchased in multiples of 100, 200, etc. In fact, before the implementation of centralized selection, the library had difficulty getting staff to order enough copies of titles that clearly had the potential to be in high demand. Granted this assessment of the centralized selection process reflects the perspective of an administrator who implemented it, but the quotes from branch librarians seem also to support this successful implementation of an innovation.

This case study also supports the importance of middle managers in the process of innovation and particularly implementation. As a result of numerous studies with Fortune 500 companies, Rosabeth Moss Kanter concludes that middle managers are the vital element in organizational innovation. They are essential to idea generation as well as playing a major role in implementation. These individuals are also referred to by terms such as early adopters of technology and opinion leaders, terms synonymous with innovators. True innovators have an impact beyond their own area of responsibility. Making changes in one's own area is simply that, efficient and effective change. Innovation is broader because it includes having an impact beyond the innovator's own organizational unit. The reason that this is innovation is that the manager has to seek support among his peers as well as higher up in the organizational structure. Thus, the manager must have a wide network of contacts from which to gain support. The manager also has to have the resources and information to make the innovation happen. ${ }^{21}$ For example, in the case of IMCPL, these middle-management librarians led the implementation of this new approach to selection. They had the insight to hire a collection development librarian to coordinate the process. They worked with the branch librarians and the vendor to implement and refine the plan. Their roles in the implementation phase of a project were to maintain the momentum of the project and foresee problems that put the project in jeopardy and resolve them.

\section{Conclusion}

Innovation is essential for the survival of libraries in the rapidly changing information world. In particular, technical services will be expected to acquire and process material more quickly than ever before and with fewer human resources. The economic environment and the speed of technological change demands and provides new alternatives. Changing patron expectations have accelerated the need for rapid evaluation, selection, and implementation of these new alternatives. The choices available from vendors will continue to proliferate. As a result, strong, competent technical services managers are an essential component to this process. These managers must continue to envision the future, to think intuitively and creatively, and to implement innovation effectively.

\section{Notes and References}

1. Carlen Ruschoff, "Cataloging's Prospects: Responding to Austerity with Innovation," Journal of Academic Librarianship 21 (January 1995): 51.

2. Lori L. Osmus, "The Transformation of Serials Cataloging, 1965-1990," in Technical 
Services Management, 1965-1990 edited by Kathryn L. Henderson, Linda C. Smith, \& Ruth C. Carter (New York: Hawthorn Press, 1996), p. 185.

3. Thomas D. Kuczmarski, Innovation: Leadership Strategies for the Competitive Edge (Lincolnwood, IL: NTC Business Books, 1996), p. 3.

4. Nicola Phillips, Innovative Management: A Pragmatic Guide to New Techniques (London: Pitman Publishing, 1993), pp. 5-17.

5. Johannah Sherrer, "Collection Development in the Revolutionized Environment," in The National Electronic Library: A Guide to the Future for Library Managers, edited by Gary M. Pitkin (Westport, CT: Greenwood Press, 1996), p. 127.

6. Colleen Cook, "After Acquisitions Automation: Managing the Human Element in a Large Library Context," Library Administration \& Management 7 (Fall 1993): 220.

7. Phillips, Innovative Management, p. 53.

8. Mary M. Rider \& Marsha Hamilton, "PromptCat Issues for Acquisitions: Quality Review, Cost Analysis and Workflow Implications," Library Acquisitions: Practice \& Theory 20 (1996): 12.

9. Kay Granskog, "PromptCat Testing at Michigan State University," Library Acquisitions: Practice \& Theory 18 (1994): 419-420.

10. Reba Leiding, "Reader's Soapbox Revisited: A Response to Dwyer's Commentary on PromptCat," Technicalities 16 (July/August 1996): 15.

11. Rider \& Hamilton, "PromptCat Issues for Acquisitions," pp. 16-17.

12. Michael A. Somers, "Causes and Effects: Shelf-Ready Processing, PromptCat and Louisiana State University," Library Acquisitions: Practice \& Theory 21 (1997): 228.

13. R. Charles Wittenberg, "'Reengineering' and the Approval Plan: New Process or New Perspective?," The Acquisitions Librarian 16 (1996): 66.

14. Julia A. Gammon, "Partnering with Vendors for Increased Productivity in Technical Services Or, Bleeding Edge Technology," Library Acquisitions: Practice \& Theory 21 (1997): 231-232.

15. Johan Olaisen, Hugo Lovhoiden, \& Olav A. Djupvik, "The Innovative Library: Innovation Theory Applied to Library Services," Libri 45 (June 1995): 82.

16. Phillips, Innovative Management, pp. 68-69.

17. Information gathered from the following sources: "Angry Hawaiian Librarians Denounce B\&T Outsourcing," American Libraries 28 (January 1997): 12; "Outsourcing in Hawaii's PLs, Lessons, Unresolved Issues," Library Hotline 25 (November 4, 1996): 1; "Hawaii/B\&T Outsourcing Deal Causing Controversy," Library Journal 121 (November 15, 1996): 12; "Baker \& Taylor Out sourcing Update" (http://www.baker-taylor.com /whatsnew/outsourc.html); "Contract Library Management Part of New B\&T Operations," Library Hotline 25 (December 2, 1996): 48; Norman Oder, "Hawaii Outsourcing Controversy Grows," Library Journal 122 (March 1, 1997): 15-16; Norman Oder, "Hawaii Cancels B\&T Outsourcing," Library Journal 122 (July 1997): 12-13.

18. Catherine Gibson, "How We Spent \$2.7 Million-With the Help of Centralized Selection," Library Journal 120 (September 1, 1995): 128.

19. Ibid, p. 129.

20. Ibid, p. 130.

21. Olaisen, Lovhoiden, \& Djupvik, "The Innovative Library," p. 81; Rosabeth Moss Kanter, The Change Masters: Innovations for Productivity in the American Corporation (New York: Simon and Schuster, 1983). 